\begin{tabular}{|c|c|c|}
\hline 7 & JOURNAL & $\begin{array}{l}e-I S S N: 2407-795 X \\
p-I S S N: 2460-2582\end{array}$ \\
\hline W & http://jurnal.unram.ac.id/index.php/jpp-ipa & $\begin{array}{l}\text { Vol 1, No, } 2 \\
\text { Juli } 2015\end{array}$ \\
\hline
\end{tabular}

\title{
PENGEMBANGAN ALAT PERAGA KOTAK ENERGI MODEL INKUIRI TERBIMBING (APKEMIT) SEBAGAI PENUNJANG PEMBELAJARAN FISIKA SMA PADA MATERI SUHU DAN KALOR
}

\author{
Budiono Basuki ${ }^{1}$, Aris Doyan ${ }^{2}$, Ahmad Harjono ${ }^{2}$ \\ Program Studi Magister Pendidikan IPA ${ }^{123}$ \\ bdnbasuki@gmail.com
}

\begin{abstract}
Key Words
APKEMIT,

development

and Gain

Score

Abstract

The purpose of this research is to develop APKEMIT as learning tool for high school physics on temperature and heat concepts. This study used Borg \& Gall approach on $R \& D$ which includes the step of development, pilot testing, and final testing. In the development stage, five APKEMIT models are produced: PKTSB, PW, PPSTUB, PK, and AB. Pilot testing stage is divided into two phase, limited testing and large scale testing. The first limited testing carried out on 6 eleventh grade science students in SMA 3 Mataram. The second phase carried on 2 groups (12 students) of accelerated tenth graders in SMA Negeri 1 Woha. Large-scale trials given to 8 groups (46 students) of tenth graders in SMA Negeri 3 Mataram. Pilot testing shows that APKEMIT is very good and ready to be used in learning activity. APKEMIT final testing stage is the stage to determine the effect of APKEMIT on the improvement of learning outcomes, which is determined by the Gain Score. Analysis shows that the gain of each model is: PKTSB Score of 0.50 (medium), PW of 0.15 (low), PPSTUB of 0.40 (medium), PK at 12:27 (low), $A B$ of 0.34 (medium) and overall Gain Score at 0:36 (medium). This development received good response from the students with score $80.8 \%$ and according to observers, learning process has been going very well. The result of research and validation of test show that the developed APKEMIT become as references in subject temperature and heats concepts.
\end{abstract}

\begin{tabular}{|c|c|}
\hline Kata Kunci & Abstrak \\
\hline $\begin{array}{l}\text { APKEMIT, } \\
\text { Pengembanga } \\
\text { n dan Gain } \\
\text { Score }\end{array}$ & $\begin{array}{l}\text { Tujuan dari penelitian ini adalah mengembangkan APKEMIT sebagai penunjang } \\
\text { pembelajaran fisika SMA pada materi suhu dan kalor. Penelitian ini menggunakan } \\
\text { pendekatan } R \text { \& D menurut Borg \& Gall, yang meliputi tahap pengembangan, uji coba, dan } \\
\text { pengujian. Tahap pengembangan dihasilkan lima aspek APKEMIT yaitu PKTSB, PW, } \\
\text { PPSTUB, PK, dan AB. Kelima aspek tersebut dinyatakan sangat layak digunakan dalam } \\
\text { pembelajaran. Tahap uji coba dilakukan dengan uji coba terbatas dan uji coba skala luas. Uji } \\
\text { coba terbatas dilakukan sebanyak dua kali kepada } 1 \text { kelompok (6 siswa) kelas XI-IPA SMA } \\
\text { Negeri } 3 \text { Mataram dan } 2 \text { kelompok (12 siswa) kelas X akselerasi SMA Negeri } 1 \text { Woha. Uji } \\
\text { coba skala luas diberikan kepada } 8 \text { kelompok (46 siswa) kelas X pada SMA Negeri } 3 \\
\text { Mataram. Pada uji coba terbatas ini dinyatakan APKEMIT sangat layak digunakan untuk } \\
\text { pembelajaran. Tahap pengujian APKEMIT adalah tahap untuk mengetahui pengaruh } \\
\text { APKEMIT terhadap peningkatan hasil belajar fisika, yang ditentukan berdasarkan Gain } \\
\text { Score. Hasil penelitian disimpulkan bahwa Gain Score tiap model adalah PKTSB sebesar } \\
\text { O,50 (sedang), PW sebesar 0,15 (rendah), PPSTUB sebesar 0,40 (sedang), PK sebesar 0.27 } \\
\text { (rendah), AB sebesar 0,34 (sedang) dan secara keseluruhan Gain Score sebesar 0.36 } \\
\text { (sedang). Pengembangan APKEMIT ini mendapat respon yang baik dari siswa sebesar } 80,8 \% \\
\text { dan menurut pengamat pembelajaran telah berjalan dengan sangat baik. Hasil penelitian dan } \\
\text { uji validasi ahli pengembangan pembelajaran dengan APKEMIT layak untuk dijadikan } \\
\text { referensi dalam pembelajaran materi suhu dan kalor. }\end{array}$ \\
\hline
\end{tabular}




\section{PENDAHULUAN}

Hasil penelitian awal yang dilakukan oleh Basuki (2014) kepada guru-guru fisika SMA di Mataram menunjukkan bahwa dalam pembelajaran yang dilakukan, guru lebih memilih metode ceramah dibandingkan metode inkuiri. Lima alasan guru memilih metode ceramah adalah: 1) sekolah tidak mempunyai peralatan laboratorium yang memadai, 2) ada peralatan tetapi laboratorium digunakan sebagai ruangan kelas, 3) eksperimen memerlukan waktu yang lebih lama, 4) tidak mempunyai laboran yang dapat membantu persiapan sebelum eksperimen, dan 5) guru kesulitan menyusun lembar kerja siswa.

Berdasarkan hasil penelitian di atas tentu sangat disayangkan, bila potensi sekolah kurang dimaksimalkan untuk mengembangkan potensi siswa. Pembelajaran secara ceramah tentu saja kurang memberi pengalaman kepada siswa untuk menunjukkan fakta dari sebuah teori. Pengalaman dari fakta sebuah teori dapat diperoleh jika pembelajaran menggunakan model inkuri. Berdasarkan aktivitas siswa, menurut Jufri (2013) pembelajaran berbasis inkuiri dibagi menjadi 3 macam, yaitu 1) Inkuiri Terstruktur: Peserta didik mengikuti dengan tepat instruksi dari pendidik untuk menyelesaikan kegiatan hands-on dengan sempurna. 2) Inkuiri Terbimbing: Peserta didik mengembangkan cara kerja untuk mencari jawaban dari pertanyaan yang dipilih. 3) Inkuiri Bebas: Peserta didik menurunkan pertanyaan tentang topik yang dipilih pendidik dan merencanakan sendiri penyelidikannya. Berdasarkan peran guru dalam pembelajaran, Standard for Science Teacher Preparation (NSTA \& AETS) dalam Sarwi \& Khanafiyah (2010) menyatakan inkuiri dikelompokkan menjadi tiga, yaitu: 1) Discovery learning: Peran guru pada saat pembelajaran adalah mengidentifikasi permasalahan dan proses, yang diikuti dengan aktivitas siswa, 2) Guided inquiry (inkuiri terbimbing): Peran guru adalah mengajukan permasalahan dan diikuti siswa menentukan proses dan penyelesaian masalah 3) Open inquiry (inkuiri bebas): Peran guru adalah memaparkan konteks penyelesaian masalah kemudian siswa mengidentifikasi dan menyelesaikan masalah.

Mempertimbangkan bahwa siswa belum terbiasa melakukan kegiatan inkuri, maka pada penelitian ini digunakan model pembelajaran dengan inkuiri terbimbing. Menurut Kholifudin (2012) dan Maliyah (2012), siswa yang belajar dengan inkuiri terbimbing melalui eksperimen memperoleh prestasi yang lebih baik dari pada siswa yang belajar dengan menggunakan demonstrasi. Wulandari (2014) lebih lanjut menyatakan bahwa hasil belajar siswa yang menerapkan model pembelajaran inkuiri terbimbing lebih tinggi dari pada siswa yang belajar dengan menggunakan metode ceramah. Pendapat diatas 
menegaskan bahwa pembelajaran dengan menggunakan inkuiri terbimbing dapat memperoleh hasil belajar yang lebih baik dibanding dengan yang menggunakan ceramah. Seorang guru yang selalu menggunakan ceramah dalam pembelajaran yang dilakukan, maka secara tidak langsung guru kurang menggali potensi siswa secara maksimal. Sehingga bila siswa menganggap pelajaran fisika itu sulit dan tidak menarik, tentunya tidak dapat disalahkan, karena guru memang kurang memberi pengalaman yang bersifat faktual.

Pendapat di atas sejalan dengan Astra et.al. (2012) dan Turnip \& Rambe (2013) menyatakan bahwa pelajaran fisika merupakan pelajaran yang sulit dan yang ingin dihindari oleh siswa, banyak siswa beranggapan bahwa fisika hanya penuh dengan rumusrumus, dalil- dalil yang sulit dipahami. Lebih lanjut Khoirudin (2013) menjelaskan bahwa $11 \%$ siswa menyatakan pelajaran fisika tidak sulit dan $89 \%$ siswa menyatakan fisika itu sulit, demikian pula $19 \%$ siswa menyatakan pembelajaran fisika itu menyenangkan dan $81 \%$ siswa menyatakan pembelajaran fisika itu tidak menyenangkan. Hal ini hanyalah sebuah penegasan tentang pengaruh dari metode ceramah dalam pembelajaran yang digunakannya secara terus menerus.

Oleh karena itu permasalahan di atas hendaknya menjadi sebuah sarana introspeksi bagi guru. Introspeksi untuk mencari dengan tepat model, metode dan media yang digunakan dalam pembelajaran agar pembelajaran yang dilakukan guru menjadi tidak menjenuhkan dan membosankan. Salah satu upaya untuk membuat pembelajaran fisika menjadi lebih baik, maka dibuatlah media pembelajaran berupa alat peraga kotak energi model inkuiri terbimbing (APKEMIT) yang digunakan untuk pembelajaran materi suhu dan kalor.

\section{METODE PENELITIAN}

\section{Jenis Penelitian}

Penelitian ini termasuk penelitian pengembangan yang menggunakan metode research and development $(\mathrm{R} \& \mathrm{D})$. Produk yang dikembangkan dalam penelitian ini berupa Alat Peraga Kotak Energi Model Inkuiri Terbimbing (APKEMIT) yang digunakan pada pembelajaran fisika SMA materi suhu dan kalor. $R \& D$ pada penelitian ini dikembangkan sesuai pendapat Borg \& Gall dalam Sutopo (2009) yang terdiri dari sepuluh tahap, seperti pada Gambar 1. 


\section{Populasi dan Sampel}

Menurut Ary et al., (1982), populasi merupakan kelompok lebih besar yang menjadi sasaran generalisasi, sedangkan sampel merupakan kelompok kecil yang diamati. Sampel ditentukan dengan teknik cluster random sampling, dimana dari 560 siswa kelas $\mathrm{X}$ semester 2 yang terbagi dalam 13 kelas, diperoleh 2 kelas yang mempunyai rata-rata nilai rapor yang sama yaitu kelas X.2 dan X.12. Kemudian kedua kelas diundi sehingga diperoleh kelas X.12 sebagai kelas ujicoba APKEMIT.

\section{Tehnik Pengumpulan Data}

1. Data Validasi Ahli

Sebelum digunakan untuk uji operasional, APKEMIT dan instrumen pendukungnya (RPP dan LKS) serta instrumen penelitian (instrumen hasil belajar fisika, instrumen respon siswa, dan lembar obeservasi) divalidasi kelayakannya oleh 3 dosen ahli. Khusus untuk APKEMIT dan LKS setelah dilakukan validasi, maka diuji coba lapangan sebanyak 2 kali untuk diketahui respon siswa terhadap APKEMIT.

2. Data Hasil Belajar Fisika

Instrumen hasil belajar fisika sebelum digunakan pada uji operasional, maka dilakukan uji coba terbatas pada 32 siswa kelas XI.IPA.PC SMA Negeri 3 Mataram dan 29 siswa kelas X.2 SMA Negeri 1 Woha. Uji coba terbatas digunakan untuk menentukan validitas, reliabilitas, tingkat kesukaran dan daya pembeda soal hasil belajar fisika. Validitas soal menurut Hartono (2012) dihitung menggunakan rumus Product Moment Pearson seperti persamaan (1).

Rumus Product Moment Pearson:

Keterangan:

$$
r_{x y}=\frac{N \Sigma X Y-(\Sigma X)(\Sigma Y)}{\sqrt{\left(N \Sigma X^{2}-(\Sigma X)^{2}\right)\left(N \Sigma Y^{2}-(\Sigma Y)^{2}\right)}}
$$

$r_{x y}=$ koefisien korelasi antara variabel $\mathrm{X}$ dan $\mathrm{Y}$

$N=$ banyak peserta tes

$X=$ skor tiap item

$Y=$ skor total

Sebuah soal dinyatakan valid apabila $r_{\text {hitung }}>r_{\text {tabel }}$

Reliabilitas soal menurut Depdiknas (2008) dihitung dengan persmaan sebagai berikut: 
Keterangan:

$$
K R-20=\frac{k}{k-1}\left[1-\frac{\sum p(1-p)}{(S D)^{2}}\right]
$$

$K R-20=$ koefisien reliabilitas tes

$p \quad=$ proporsi subyek yang menjawab item dengan benar

$k \quad=$ jumlah butir soal

$$
(S D)^{2}=\frac{\Sigma(X-\bar{X})^{2}}{N}
$$

Sebuah soal dinyatakan reliabel apabila $r_{\text {hitung }}>r_{\text {tabel }}$

Tingkat kesukaran soal menurut Depdiknas (2008) ditentukan dengan persamaan berikut:

Keterangan:

$$
T K=\frac{B}{J s}
$$

$T K=$ tingkat kesukaran

$B=$ jumlah siswa yang menjawab soal dengan benar

$J_{S}=$ jumlah siswa yang mengikuti tes

Tabel 1. Kriteria Indeks Kesukaran Soal

\begin{tabular}{cc}
\hline Klasifikasi & Kriteria \\
\hline $0,00-0,30$ & Sukar \\
$0,31-0,70$ & Sedang \\
$0,71-1,00$ & Mudah \\
\hline & (Nitko-Depdiknas, 2008)
\end{tabular}

Daya pembeda soal menurut Depdiknas (2008) ditentukan dengan persamaan berikut:

$$
D P=\frac{B A-B B}{\frac{1}{2} N}
$$

Keterangan:

$$
\begin{aligned}
& D P=\text { daya pembeda soal } \\
& B A=\text { jumlah jawaban benar pada kelompok atas } \\
& B B=\text { jumlah jawaban benar pada kelompok bawah } \\
& N \quad=\text { jumlah siswa yang mengerjakan tes }
\end{aligned}
$$

Tabel 2. Kriteria Daya Pembeda Soal

\begin{tabular}{cl}
\hline Klasifikasi & \multicolumn{1}{c}{ Kriteria } \\
\hline $0,40-1,00$ & Soal diterima baik \\
$0,30-0,39$ & Soal diterima tetapi perlu diperbaiki \\
$0,20-0,29$ & Soal diperbaiki \\
$0,19-0,00$ & Soal tidak dipakai/dibuang \\
\hline & Crocker \& Algina-Depdiknas (2008)
\end{tabular}

Untuk mengetahui peningkatan hasil belajar (Gain Score), maka harus diketahui nilai pretest dan posttest hasil belajar fisika. Pretest diberikan kepada siswa kelas X.12 
SMA Negeri 3 Mataram sebanyak 46 siswa. Pretest dilakukan sebelum kegiatan pembelajaran suhu dan kalor, sedangkan posttest diberikan setelah pembelajaran berakhir. Menurut Hake dalam Evawani, et.al. (2013), nilai Gain dihitung dengan persamaan:

$$
\langle g\rangle=\frac{S_{\text {post }}-S_{\text {pre }}}{S_{\text {maks }}-S_{\text {pre }}}
$$

6)

Keterangan:

$$
\begin{array}{ll}
\langle g\rangle & =\text { skor Gain } \\
S_{\text {post }} & =\text { skor post test } \\
S_{\text {pre }} & =\text { skor pre test } \\
S_{\text {maks }} & =\text { skor maksimal }
\end{array}
$$

Tabel 3. Kriteria Skor Gain

\begin{tabular}{cc}
\hline Klasifikasi Skore Gain & Kategori \\
\hline $0,7<\langle g\rangle \leq 1$ & Tinggi \\
$0,3<\langle g\rangle \leq 0,7$ & Sedang \\
$\langle g\rangle \leq 0,3$ & Rendah \\
\hline \multicolumn{2}{c}{ Evawani, et al. 2013 }
\end{tabular}

3. Data Respon Siswa

Data respon siswa diperoleh melalui penyebaran angket kepada siswa setelah pembelajaran menggunakan APKEMIT. Angket berisi pernyataan tentang: 1) Kemenarikan APKEMIT, 2) Kemudahan penggunaan APKEMIT, 3) Peran APKEMIT dalam pembelajaran suhu dan kalor dan 4) Keselamatan menggunakan APKEMIT. Penentuan kelayakan APKEMIT digunakan kriteria penilaian sebagai berikut:

Tabel 4. Kriteria Respon siswa

4. Data Penilaian Observer

\begin{tabular}{ll}
\hline Rentang skor & \multicolumn{1}{c}{ Kriteria } \\
\hline $1,00-1,75$ & tidak layak digunakan \\
$1,76-2,50$ & kurang layak digunakan \\
$2,51-3,25$ & layak digunakan \\
$3.26-4,00$ & sangat layak digunakan \\
\hline
\end{tabular}

Data penilaian observer adalah data penilaian proses pembelajaran yang dilakukan oleh pengamat. Penilaian dilakukan terhadap: 1) Rencana Pembelajaran, 2) Pelaksanaan Pembelajaran, 3) Keterampilan Melaksanakan Hubungan Pribadi, dan 4) Aktivitas Siswa Dalam Pembelajaran. 

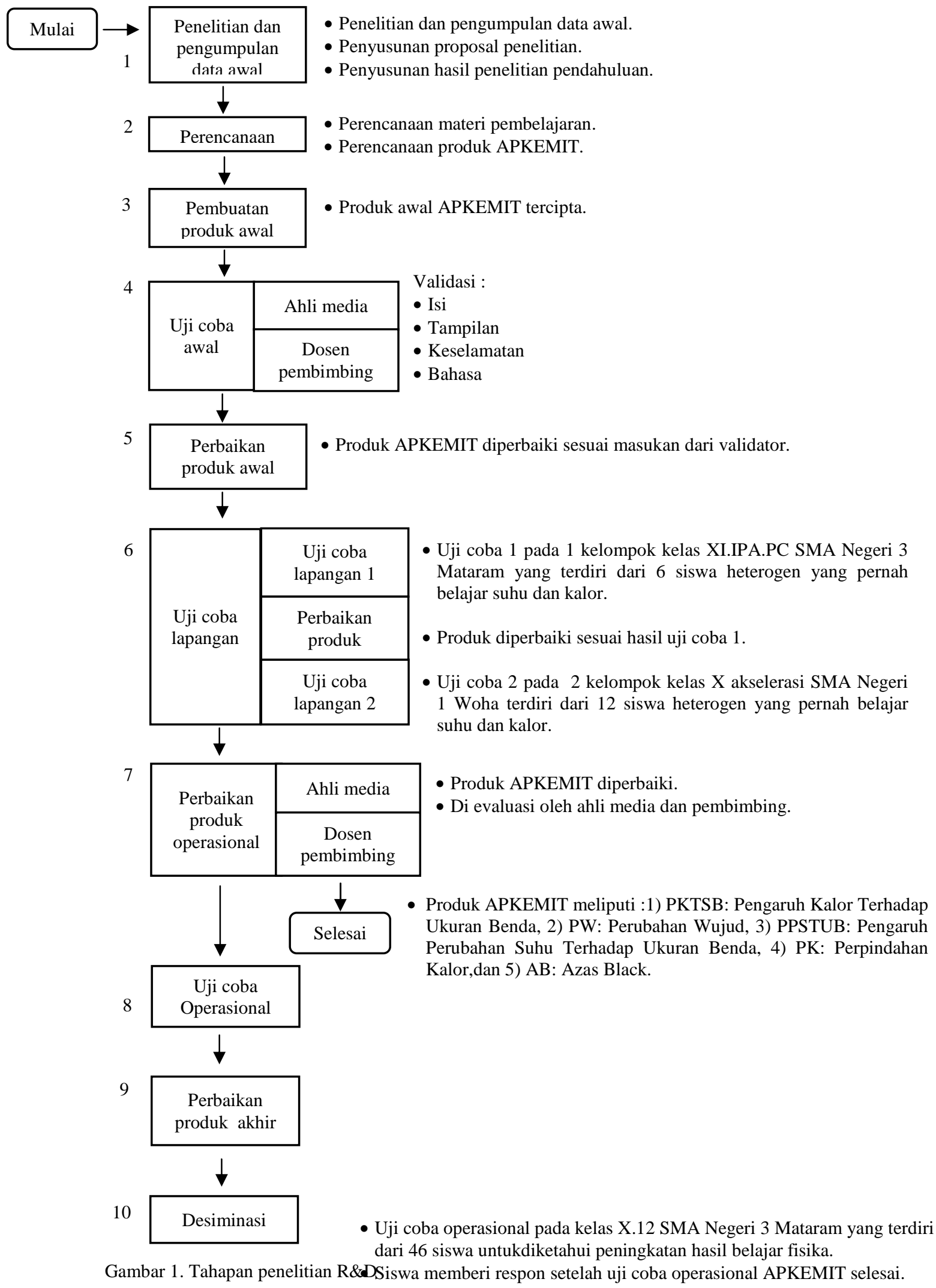


\section{HASIL PENELITIAN DAN PEMBAHASAN}

1. Hasil Validasi Ahli

Hasil validasi dari 3 dosen ahli menggunakan skala penilaian 4, terhadap APKEMIT berdasarkan kualitas teknik, kualitas isi dan tujuan, kualitas pembelajaran dan instruksional, diperoleh rata-rata skor sebesar 3,83 dengan kategori sangat layak digunakan. Kriteria sangat layak digunakan juga diperoleh oleh instrumen pendukung berupa RPP dengan rata-rata skor 3,83 dan LKS dengan rata-rata skor 3,93. Hasil respon siswa pada uji coba pertama dinyatakan APKEMIT layak digunakan, sedangkan pada uji coba kedua dinyatakan sangat layak digunakan. Sehingga secara keseluruhan dapat dinyatakan APKEMIT sangat layak digunakan untuk pembelajaran fisika SMA materi suhu dan kalor.

2. Hasil Belajar Fisika

Hasil analisis terhadap validitas, reliabilitas, tingkat kesukaran dan daya pembeda dari 30 soal instrumen hasil belajar fisika diperoleh: 1) Sebanyak 27 soal memenuhi syarat validitas dan 3 soal tidak memenuhi syarat, 2) Uji reliabilitas diperoleh seluruh soal (30 soal) dinyatakan reliabel, 3) Uji tingkat kesukaran diperoleh, 11 soal dinyatakan mudah, 13 soal dinyatakan sedang dan 6 soal dinyatakan sukar, 4) Selanjutnya pada uji daya pembeda diperoleh 5 soal diterima baik, 22 soal diperbaiki dan 3 soal dibuang. Hal ini sesuai dengan Arikunto dalam Amalia \& Widayati (2012) dan dipertegas kembali oleh Arikunto dalam Arizona (2013).

Soal yang telah memenuhi syarat selanjutnya digunakan untuk mengukur kemampuan awal siswa (pretest). Setelah dilakukan pretest, maka selanjutnya dilakukan pembelajaran menggunakan APKEMIT sebanyak 5 kali pertemuan. Kelima pertemuan tersebut adalah 1) PKTSB, 2) PW, 3) PPSTUB, 4) PK,dan 5) AB. Posttest dilakukan pada pertemuan keenam dengan menggunakan soal pretest yang sudah diperbaiki. Hasil dari pretest dan posttest dapat ditampilkan pada gambar 2 berikut.

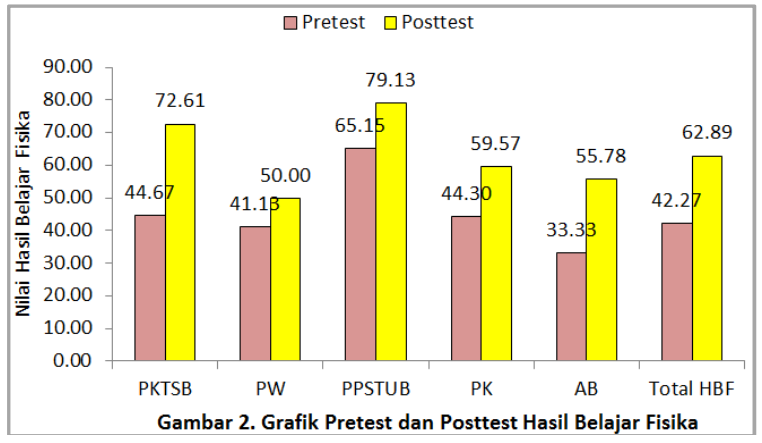


Data pretest dan posttest digunakan untuk menghitung Gain Score seperti pada tabel 5.

\begin{tabular}{lrrrr}
\multicolumn{6}{l}{ Tabel 5. Data Gain Score } \\
\multicolumn{1}{c}{ Sumber Data } & Pretest & Posttest & Gain Score & Kriteria \\
\hline PKTSB & 44,67 & 72,61 & 0,50 & Sedang \\
PW & 41,13 & 50,00 & 0,15 & Rendah \\
PPSTUB & 65,15 & 79,13 & 0,40 & Sedang \\
PK & 44,30 & 59,57 & 0,27 & Rendah \\
AB & 33,33 & 55,78 & 0,34 & Sedang \\
Total HBF & 42,27 & 62,89 & 0,36 & Sedang \\
\hline
\end{tabular}

Tabel 5 di atas menjelaskan bahwa APKEMIT dapat digunakan untuk pembelajaran materi suhu dan kalor dengan kriteria sedang.

Gain Score hasil belajar fisika dapat ditampilkan pada gambar 3 berikut.

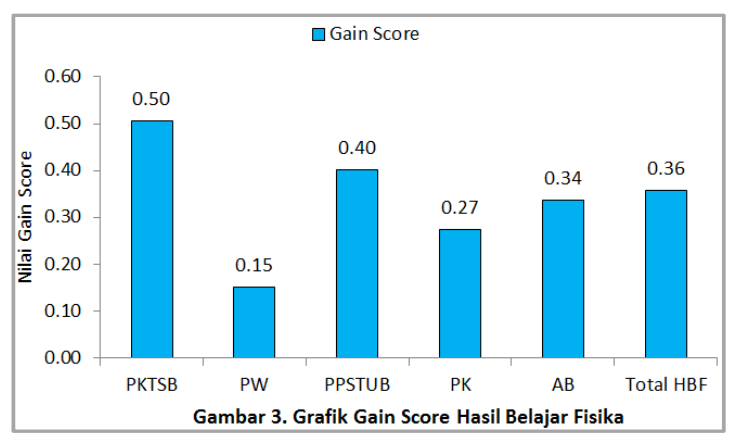

3. Hasil Respon Siswa

Hasil respon siswa terhadap pembelajaran dengan menggunakan APKEMIT adalah sebesar 3,46 (86,5\%) siswa menyatakan menarik, 3,14 (78,5\%) siswa menyatakan mudah digunakan, $3,20(80,0 \%)$ siswa menyatakan berperan dalam pembelajaran suhu dan kalor, 3,13 (78,3\%) siswa menyatakan aman digunakan dan secara keseluruhan $3.23(80,8 \%)$ siswa memberi respon yang baik.

4. Hasil Penilaian Observer

Penilaian terhadap proses pembelajaran yang dilakukan oleh pengamat atau observer memperoleh hasil 1) Rencana pembelajaran memperoleh skor 3,94 dengan kriteria sangat baik, 2) Pelaksanaan pembelajaran memperoleh skor 3,93 dengan kriteria sangat baik, 3) Keterampilan melaksanakan hubungan pribadi memperoleh skor 3,96 dengan kriteria sangat baik, 4) Aktivitas siswa dalam pembelajaran memperoleh skor 3,81 dengan sangat baik. Sehingga secara keseluruhan menurut pengamat, proses belajar mengajar 


\section{PENUTUP}

Pengembangan media pembelajaran fisika SMA materi suhu dan kalor menghasilkan lima aspek APKEMIT yaitu: 1) PKTSB: Pengaruh Kalor Terhadap Ukuran Benda, 2) PW: Perubahan Wujud, 3) PPSTUB: Pengaruh Perubahan Suhu Terhadap Ukuran Benda, 4) PK: Perpindahan Kalor,dan 5) AB: Azas Black. Penggunaan APKEMIT dalam pembelajaran dapat meningkatkan hasil belajar fisika dengan kriteria Gain Score tiap model: PKTSB sebesar 0,50 (sedang), PW sebesar 0,15 (rendah), PPSTUB sebesar 0,40 (sedang), PK sebesar 0.27 (rendah), AB sebesar 0,34 (sedang) dan secara keseluruhan Gain Score sebesar 0.36 (sedang). Hasil ini didukung oleh respon baik dari siswa sebesar $80,8 \%$ dan proses pembelajaran telah berlangsung dengan sangat baik.

\section{DAFTAR PUSTAKA}

Amalia, A.N. \& Widayati, A. 2012. Analisis Butir Soal Tes Kendali Mutu Kelas XII SMA Matapelajaran Ekonomi Akuntansi di Kota Yogyakarta Tahun 2012. Jurnal Pendidikan Akuntansi Indonesia, Vol. X, No. 1.

Arizona, K. 2013. Pengaruh Implementasi Media Tiga Dimensi Kemagnetan Berbasis Inkuiri (MTDKBI) Melalui Strategi Kooperatif Terhadap Kecakapan Sosial, Sikap Ilmiah, dan Hasil Belajar Kognitif Fisika Siswa SMP Kelas IX. Tesis. Program Studi Magister Pendidikan IPA - Program Pascasarjana - Universitas Mataram.

Ary, D., Jacobs, L.C., \& Razavieh, A. 1982. Pengantar Penelitian Dalam Pendidikan. Surabaya: Usaha Nasional.

Astra, I.M., Umiatin, \& Ruharman, D. 2012. Aplikasi Mobile Learning Fisika Dengan Menggunakan Adobe Flash Sebagai Media Pembelajaran. Jurnal Pendidikan dan Kebudayaan. Vol. 18, Nomor 2, Juni 2012

Depdiknas. 2008. Perangkat Penilaian Kurikulum Tingkat Satuan Pendidikan (KTSP) Sekolah Menengah Atas (SMA). Jakarta: Direktorat Pembinaan Sekolah Menengah Atas - Dirjen MPDM.

Evawani, T., Rahayu, E. S. \& Retnoningsih, A. 2013. Pengembangan Perangkat Pembelajaran Bermakna Menggunakan Lembar Kerja Siswa Divergen Pada Materi Ciri-ciri Makhluk Hidup. Journal of Educational Research and Evaluation. ISSN 2252 $-6420$

Jufri, A.W. 2013. Belajar dan Pembelajaran Sains. Bandung, Pustaka Reka Ciptakan. 2013. 
Khoirudin, N., Wahyuningsih, D., \& Teguh, D. 2013. Pengembangan Media Pembelajaran Dengan Menggunakan Aplikasi Mindfet Mindmanager 9 Untuk Siswa SMA Pada Pokok Bahasan Alat Optik. Jurnal Pendidikan Fisika. Vol.1 No.1 halaman 1. ISSN: $2338-0691$

Kholifudin, M.Y. 2012. Pembelajaran Fisika dengan Inkuiri Terbimbing Melalui Metode Eksperimen dan Demonstrasi Ditinjau dari Gaya Belajar Siswa. Prosiding Pertemuan Ilmiah XXVI HFI Jateng \& DIY, Purworejo 14 April 2012. ISSN : 0853-0823

Hartono. 2012. Statistik untuk Penelitian. Yogyakarta: Pustaka Belajar

Maliyah, N., Sunarno, W., \& Suparmi. 2012. Pembelajaran Fisika Dengan Inkuiri Terbimbing Melaui Metode Eksperimen dan Demontrasi Diskusi Ditinjau dari Kemampuan Matematik dan Kemampuan Verbal Siswa. Jurnal Inkuiri. ISSN: 22527893, Vol 1, No 3 (hal 227-234).

Sarwi \& Khanafiyah, S. 2010. Pengembangan Keterampilan Kerja Ilmiah Mahasiswa Calon Guru Fisika Melalui Eksperimen Gelombang Open Inquiry, Jurnal Pendidikan Fisika Indonesia 6 (2010) 115-122 ISSN: 1693-1246.

Sutopo, Hadi. 2009. Pengembangan Model Pembelajaran Pembuatan Aplikasi Multimedia Khususnya Puzzel Game Pada Mata Kuliah Multimedia. Disertasi. Program Pascasarjana. Universitas Negeri Jakarta.

Turnip, B.M. \& Rambe, F. 2013). Pengaruh Model Pembelajaran Problem Solving Dengan Integrasi Karakter Terhadap Pembentukan Karakter dan Hasil Belajar Siswa Pada Materi Pokok Persamaan Gas Ideal di Kelas XI SMA Swasta Sri Langkat Kecamatan Tanjung Pura T. P. 2011 / 2012. Jurnal INPAFI. Volume 1, Nomor 1.

Widoyoko, S.E.P 2012. Teknik Penyusunan Instrumen Penelitian. Yogyakarta, Pustaka Pelajar.

Wulandari, Ratri. 2014. Pengaruh Model Pembelajaran Inkuiri Terbimbing terhadap Hasil Belajar Siswa SMAN 1 Pasuruan. Tesis. Pendidikan Geografi, Pascasarjana Universitas Negeri Malang. 